\title{
Phthalimides as Exceptionally Efficient Single Electron Transfer Acceptors in Reductive Coupling Reactions Promoted by Samarium Diiodide
}

2007

Vol. 9, No. 26

5445-5448

\author{
Tatiana Vacas, ${ }^{\dagger}$ Eleuterio Álvarez, ${ }^{\ddagger}$ and Jose Luis Chiara*,† \\ Instituto de Química Orgánica General, CSIC, Juan de la Cierva, 3, E-28006 Madrid, \\ Spain, and Instituto de Investigaciones Químicas, CSIC, Americo Vespucio s/n, Isla de \\ la Cartuja, E-41092 Sevilla, Spain
}

jl.chiara@iqog.csic.es

Received September 25, 2007

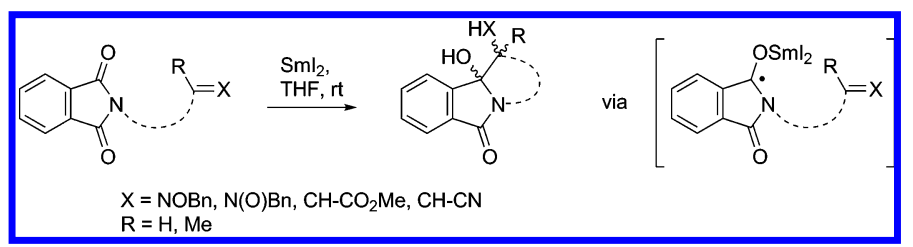

Experimental and theoretical evidence shows that phthalimides are highly efficient single electron transfer acceptors in reactions promoted by samarium diiodide, affording ketyl radical anion intermediates, which participate in high-yielding inter- and intramolecular reductive coupling processes with different radicophiles including imides, oxime ethers, nitrones, and Michael acceptors.

The reactions of different types of carbonyl compounds, including ketones, aldehydes, esters, acid chlorides, and acid anhydrides, with samarium(II) iodide have been extensively studied in the past 25 years. ${ }^{1}$ Whereas amides exhibit in general a low reactivity profile, typically requiring thermal conditions and the presence of samarium metal to participate in homo- or cross-coupling reactions, ${ }^{2}$ imides have proven to be much more reactive. Thus, cyclic imides ${ }^{3}$ readily suffer intra- and intermolecular Barbier-type reactions ${ }^{4}$ in the presence of samarium diiodide at room temperature, and

\footnotetext{
† Instituto de Química Orgánica General.

Instituto de Investigaciones Químicas.

(1) For recent reviews, see: (a) Edmonds, D. J.; Johnston, D.; Procter, D. J. Chem. Rev. 2004, 104, 3371-3403. (b) Kagan, H. B. Tetrahedron 2003, 59, 10351-10372. (c) Steel, P. G. J. Chem. Soc., Perkin Trans. I 2001, 2727-2751. (d) Krief, A.; Laval, A.-M. Chem. Rev. 1999, 99, 745777. (e) Molander, G. A.; Harris, C. R. Tetrahedron 1998, 54, 3321-3354. (f) Molander, G. A.; Harris, C. R. Chem. Rev. 1996, 96, 307-338.

(2) (a) Ogawa, A.; Takami, N.; Sekiguchi, M.; Ryu, I.; Kambe, N.; Sonoda, N. J. Am. Chem. Soc. 1992, 114, 8729-8730. (b) Ogawa, A.; Takami, N.; Nanke, T.; Ohya, S.; Hirao, T. Tetrahedron 1997, 53, 1289512902. (c) Honda, T.; Ishikawa, F. Chem. Commun. 1999, 1065-1066. (d) McDonald, C. E.; Galka, A. M.; Green, A. I.; Keane, J. M.; Kowalchick, J. E.; Micklitsch, C. M.; Wisnoski, D. D. Tetrahedron Lett. 2001, 42, 163166. (e) Xu, X.; Zhang, Y. Tetrahedron 2002, 58, 503-506.
}

$N$-acyl lactams ${ }^{5}$ and $N$-alkylphthalimides ${ }^{6}$ efficiently crosscouple with aldehydes and ketones intra- or intermolecularly under similarly mild conditions. More recently, $\mathrm{N}$-acyloxazolidinones have been successfully cross-coupled with activated alkenes using $\mathrm{SmI}_{2} \cdot{ }^{7}$ In these reactions, the imide is generally thought to play the role of an electrophilic,

(3) Cyclic imides participate in reductive coupling reactions under different conditions. (a) Photochemical: Kanaoka, Y.Acc. Chem. Res. 1978 11, 407-413. Yoon, U. C.; Mariano, P. S. Acc. Chem. Res. 2001, 34, 523533. (b) Electrochemical: Leedy, D. W.; Muck, D. L. J. Am. Chem. Soc. 1971, 93, 4264-4270. Orzesko, D. W.; Maurin, J. K.; Niedzwiecka-Kornas, A.; Kazimierczuk, Z. Tetrahedron 1998, 54, 7517-7524. (c) Low valent titanium reagents: Fürstner, A.; Jumbam, D. N. Tetrahedron 1992, 48, 5991-6010. Lee, J.; Ha J. D.; Cha, J. K. J. Am. Chem. Soc. 1997, 119 , 8127-8128. Ollero, L.; Mentink, G.; Rutjes, F. P. J. T.; Speckamp, W. N.; Hiemstra, H. Org. Lett. 1999, 1, 1331-1334. Cao, B.; Xiao, D.; Joullié, M. M. Org. Lett. 1999, 1, 1799-1801. Sung, M. J.; Lee, C.-W.; Cha, J. K. Svnlett 1999, 561-562. Santra, S.; Masalov, N.; Epstein, O. L.; Cha, J. K. Org. Lett. 2005, 7, 5901-5904.

(4) (a) Ha, D.-C. Tetrahedron Lett. 1996, 37, 2577-2580. (b) Ha, D.C.; Yun, C.-S.; Lee, Y. J. Org. Chem. 2000, 65, 621-623. (c) Farcas, S.; Namy, J.-L. Tetrahedron Lett. 2001, 42, 879-882.

(5) Farcas, S.; Namy, J.-L. Tetrahedron Lett. 2000, 41, 7299-7302.

(6) (a) Yoda, H.; Matsuda, K.; Nomura, H.; Takabe, K. Tetrahedron Lett. 2000, 41, 1775-1780. (b) Yoda, H.; Nakahama, A.; Koketsu, T.; Takabe, K. Tetrahedron Lett. 2002, 43, 4667-4669. 
C-radical, or carbanion acceptor, ${ }^{4,6 a, 7 b}$ except for the case of $\mathrm{N}$-acyl lactams, where an acyl samarium species formed by reductive cleavage of the lactam ring has been proposed ${ }^{5}$ as

Scheme 1. Intra- and Intermolecular Reductive Coupling Reactions of $\mathrm{N}$-Substituted Phthalimides Promoted by $\mathrm{SmI}_{2}$<smiles>O=C1c2ccccc2C(=O)N1CCN1C(=O)c2ccccc2C1=O</smiles>

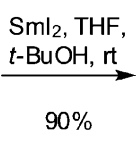

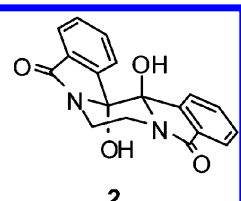<smiles>[R]C(CN1C(=O)c2ccccc2C1=O)=N[O-]</smiles>

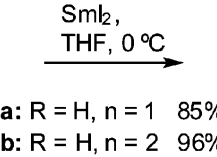
c: $R=M e, n=178 \%$<smiles>[R]C1CCN2C(=O)c3ccccc3[C@]1(O)C2(O)O</smiles><smiles>CCCCN=C(C)c1ccccc1N1C(=O)c2ccccc2C1=O</smiles>

$\mathrm{Sml}_{2}, \mathrm{THF}$ $t$ - $\mathrm{BuOH},-30^{\circ} \mathrm{C}$ $70 \%$<smiles>CN(C)[C@]1(O)c2ccccc2N2C(=O)c3ccccc3[C@]21c1ccccc1</smiles><smiles>[Y]C(CCN1C(=O)c2ccccc2C1=O)=[N+]([O-])Cc1ccccc1</smiles><smiles>CC1(N(O)O)CCN2C(=O)c3ccccc3[C@]21Br</smiles>
8<smiles>N#CCC[C@H](CCC(=O)O)C1(O)NC(=O)c2ccccc21</smiles>
b: $n=283 \%(1: 0)$

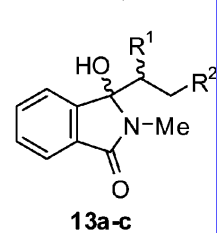

11

$12 a-c$

a: $\mathrm{R}^{1}=\mathrm{H}, \mathrm{R}^{2}=\mathrm{CO}_{2} \mathrm{Me} \quad 88 \%$

b: $R^{1}=H, R^{2}=C N 97 \%$

c: $\mathrm{R}^{1}=\mathrm{Ph}, \mathrm{R}^{2}=\mathrm{CO}_{2} \mathrm{Me} \quad 93 \%(1: 1)$

intermediate. In 2005, on the basis of new experimental evidence, we considered an alternative mechanistic hypothesis for the cross-coupling of phthalimides and carbonyl compounds promoted by $\mathrm{SmI}_{2}$, which involved the chemoselective single electron transfer reduction of the imide to give

(7) (a) Jensen, C. M.; Lindsay, K. B.; Taaning, R. H.; Karaffa, J.; Hansen, A. M.; Skrydstrup, T. J. Am. Chem. Soc. 2005, 127, 6544-6545. (b) Hansen, A. M.; Lindsay, K. B.; SudhadeviAntharjanam, P. K.; Karaffa, J.; Daasbjerg, K.; Flowers, R. A.; Skrydstrup, T. J. Am. Chem. Soc. 2006, 128, 96169617. (c) Karaffa, J.; Lindsay, K. B.; Skrydstrup, T. J. Org. Chem. 2006, 71, 8219-8226. (d) Lindsay, K. B.; Ferrando, F.; Christensen, K. L.; Overgaard, J.; Roca, T.; Bennasar, M. L.; Skrydstrup, T. J. Org. Chem. 2007, 72, 4181-4188. a ketyl radical-anion intermediate. ${ }^{8,9}$ This alternative hypothesis was supported by DFT calculations on simple model compounds. On the basis of the new mechanistic evidence, we set out to study the viability of a series of unprecedented reductive coupling reactions promoted by $\mathrm{SmI}_{2}$ involving $\mathrm{N}$-substituted phthalimides and diverse C-radical acceptors.

We report herein the first results of this study, which show that phthalimides are in effect highly efficient single electron transfer acceptors in samarium diiodide-promoted intramolecular homocoupling reactions and in intra- or intermolecular cross-coupling reactions with oxime ethers, nitrones, and activated alkenes, affording the expected $\alpha$-hydroxy lactams under very mild conditions and in good to very high yields (Scheme 1). As a first experiment, we assayed the intramolecular homocoupling reaction of diphthaloyl ethylenediamine derivative $\mathbf{1}$ in the presence of $\mathrm{SmI}_{2}$ and $t-\mathrm{BuOH}$ at room temperature. The reaction took place smoothly to afford the expected coupling product $\mathbf{2}^{10}$ in very high yield and as a single diastereoisomer. The trans relative stereochemistry of 2 was unambiguously determined by X-ray diffraction (Figure 1). ${ }^{11}$ The coupling reaction could be performed at a

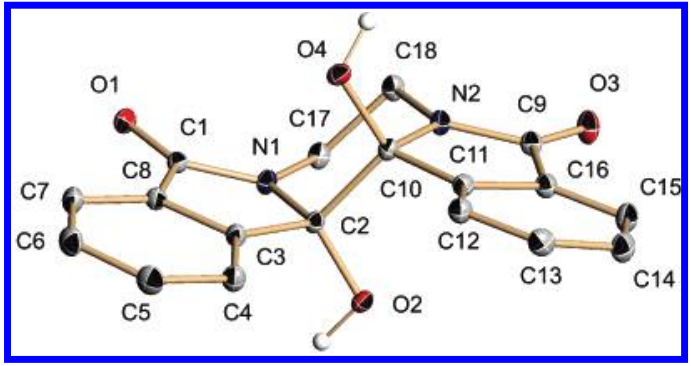

Figure 1. X-ray structure of compound 2.

lower temperature $\left(-30{ }^{\circ} \mathrm{C}\right)$ with equally high yield $(80 \%)$, attesting to the high reactivity of the phthalimido group under these very mild reductive conditions. We next tested the intramolecular cross-coupling with oxime ethers. Both aldehyde- (3a,b) and ketone-derived (3c, 5) oxime ethers (as $E / Z$ mixtures of isomers) performed very efficiently to produce the expected five- and six-membered heterocyclic $O$-benzyl hydroxylamine products $\mathbf{4} \mathbf{a}-\mathbf{c}$ and $\mathbf{6}$, respectively, in high yield and as single diastereoisomers. The cis relative stereochemistry of $\mathbf{4 c}$ was unambiguously determined by X-ray diffraction (Figure 2), ${ }^{11}$ and those of the other products in this series were only tentatively assigned from this. The observed stereoselectivity differs from that found in the related cross-coupling of oxime ethers with aldehydes and

(8) Chiara, J. L.; Garcia, A.; Cristobal-Lumbroso, G. J. Org. Chem. 2005, $70,4142-4151$

(9) Ha has previously suggested the intermediacy of a ketyl radical anion in the $\mathrm{SmI}_{2}$-promoted reductive cyclization of $\mathrm{N}$-haloalkyl phthalimides. ${ }^{4 \mathrm{a}}$

(10) Compound 2 has been prepared previously in low yield (19\%) under photochemical conditions: Sato, K.; Kanaoka, Y. Chem. Pharm. Bull. 1978, 26, 989-991.

(11) See Supporting Information. 


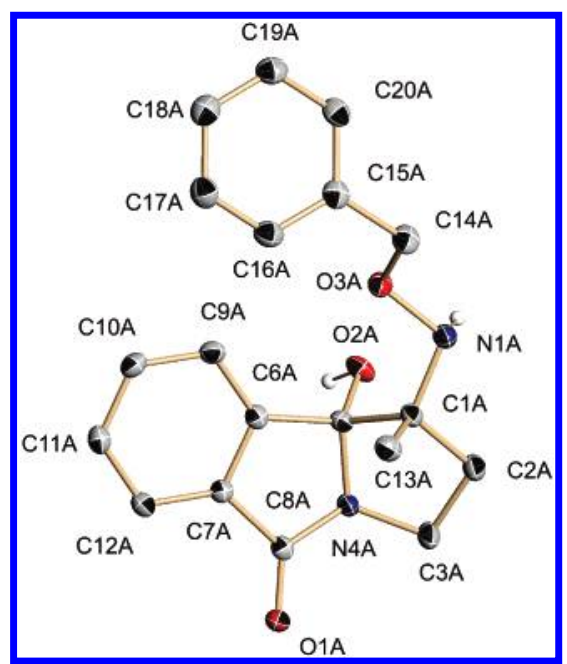

Figure 2. X-ray structure of compound $\mathbf{4 c}$.

ketones, which gives preferentially the trans product. ${ }^{12}$ Nitrone 7 (as a 1:1 E/Z mixture of isomers) also cyclized smoothly to afford $\mathrm{N}$-benzyl-hydroxylamine $\mathbf{8}$ in moderate yield. ${ }^{13}$ However, in this case a 3:2 mixture of cyclic diasterereoisomers resulted. Single crystals of the minor isomer appropriate for X-ray diffraction studies ${ }^{11}$ could be obtained by fractional crystallization of the mixture in $\mathrm{MeOH}$, which allowed us to assign the cis stereochemistry to this isomer (Figure 3) ${ }^{14}$ We next examined the intramolecular coupling with activated alkenes. Thus, cyclization of $\alpha, \beta$-unsaturated esters $\mathbf{9 a}, \mathbf{b}$ afforded the expected products $\mathbf{1 0 a}, \mathbf{b}$ in moderate and high yield, respectively. The cyclization of 9a gave a mixture of diastereoisomers, whereas that of $9 \mathbf{b}$ was completely stereoselective. Unfortunately, we were unable to obtain appropriate crystals of these products for $\mathrm{X}$-ray diffraction, and their stereochemistry could not be determined by NOE ${ }^{1} \mathrm{H}$ NMR spectroscopy. Surprisingly, as observed for the case of the oxime ethers couplings, the six-membered heterocyclic products are formed in significantly better yields than their five-membered counterparts, implying that an optimum trajectory of approach between the imide radical anion and the radicophile can only be attained when a sufficiently large ring is being formed. An intermolecular version of this coupling reaction was also

(12) (a) Chiara, J. L.; Marco-Contelles, J.; Khiar, N.; Gallego, P.; Destabel, C.; Bernabe, M. J. Org. Chem. 1995, 60, 6010-6011. (b) MarcoContelles, J.; Gallego, P.; Rodriguez-Fernandez, M.; Khiar, N.; Destabel, C.; Bernabe, M.; Martinez-Grau, A.; Chiara, J. L. J. Org. Chem. 1997, 62, 7397-7412. (c) Storch de Gracia, I.; Bobo, S.; Martin-Ortega, M. D.; Chiara, J. L. Org. Lett. 1999, 1, 1705-1708. (d) Bobo, S.; Storch de Gracia, I.; Chiara, J. L. Synlett 1999, 1551-1554.

(13) For previously reported reductive coupling reactions of nitrones promoted by $\mathrm{SmI}_{2}$, see the recent review: (a) Cardona, F.; Goti, A. Angew. Chem. Int. Ed. 2005, 44, 7832-7835 and the following: (b) Desvergnes, S.; Py, S.; Vallee, Y. J. Org. Chem. 2005, 70, 1459-1462. (c) Ebran, J. P.; Hazell, R. G.; Skrydstrup, T. Chem. Commun. 2005, 5402-5404. (d) Masson, G.; Philouze, C.; Py, S. Org. Biomol. Chem. 2005, 3, 2067-2069. (e) Desvergnes, S.; Desvergnes, V.; Martin, O. R.; Itoh, K.; Liu, H. W.; Py, S. Bioorg. Med. Chem. 2007, 15, 6443-6449.

(14) Interconversion of diastereoisomers via isomerization of the aminal center is a slow process that takes several weeks at room temperature in $\mathrm{CDCl}_{3}$ solution in the absence of added acid catalysts.

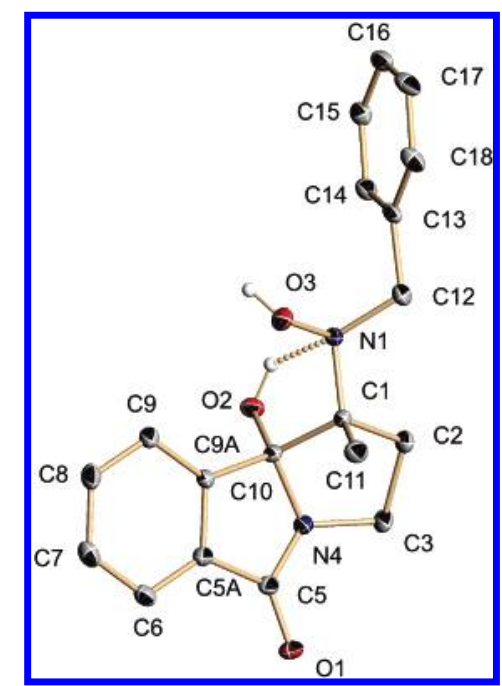

Figure 3. X-ray structure of the minor diastereoisomer of compound 8.

assayed. Thus, the dropwise addition of a THF solution of $\mathrm{SmI}_{2}$ and $t$-BuOH to a mixture of $N$-methylphthalimide (11) and a 4-fold excess of a monosubstituted $(\mathbf{1 2 a}, \mathbf{b})$ or a 1,2disubstituted (12c) Michael acceptor at low temperature yielded the expected coupling products $\mathbf{1 3 a}-\mathbf{c}$ in very good yields. Not surprisingly, the 1,2-disubstituted alkene afforded a mixture of diastereoisomers with low stereoselectivity.

From a mechanistic point of view, these reductive coupling reactions could be explained as resulting from the initial single electron transfer reduction of either the imido group or the other reducible functional group present in our substrates. The relative thermodynamic ease of reduction of different functional groups might be inferred from available solution redox potentials for organic molecules containing each of these groups. ${ }^{15}$ However, care should be taken when comparing electrochemical data obtained under different experimental conditions due to the sensitivity of the halfwave reduction potential values to the solvent, $\mathrm{pH}$, and supporting electrolyte used. For this reason, we have performed quantum mechanical DFT calculations on simple model systems representing the different functional groups present in our substrates to determine their relative susceptibility to suffer single electron transfer reduction. Table 1 shows the vertical electron affinity (VEA) and the adiabatic electron affinity (AEA) calculated at the UB3LYP/6-311G$(d, p)$ level in gas phase for these model compounds. ${ }^{22,23}$ The

(15) The $E_{1 / 2}^{\text {red }}$ values reported for some of our substrates are the following: $N$-methylphthalimide, $-1.39 \mathrm{~V}$ (in MeCN, first wave); ${ }^{16}$ ethyl cinnamate, $-1.88 \mathrm{~V}$ (in DMF); ${ }^{17}$ acrylonitrile, -2.83 (in THF); ${ }^{18}$ methyl acrylate, -2.93 (in THF). ${ }^{18}$ Values reported for oximes ${ }^{19}$ and nitrones ${ }^{20}$ are strongly pH-dependent and less negative than those above but correspond to the initial electroreductive cleavage of the $\mathrm{N}-\mathrm{O}$ bond in protic solvents, a process facilitated by protonation that is not observed under our reaction conditions. Shono ${ }^{21}$ has shown that oxime ethers are not electrochemically reducible under the same conditions as they are coupled to ketones. Moreover, we have previously observed that $N$-alkylphthalimides are reduced faster than oxime ethers and ketones by $\mathrm{SmI}_{2} .{ }^{8}$

(16) Hartmann, K. H.; Troll, T. Tetrahedron 1995, 51, 4655-4664. 
Table 1. Calculated UB3LYP/6-311G(d,p) Gas-Phase Vertical Electron Affinities (VEA) and Adiabatic Electron Affinities (AEA) for Representative Model Compounds

\begin{tabular}{lll}
\hline \multicolumn{1}{c}{ compound } & \multicolumn{1}{c}{$\mathrm{VEA}^{a}(\mathrm{eV})$} & \multicolumn{1}{c}{$\mathrm{AEA}^{b}(\mathrm{eV})$} \\
\hline$N$-methylphthalimide & $0.52^{c}$ & $0.78^{c}$ \\
acetaldehyde $O$-methyl oxime & $-2.53^{c}$ & $d$ \\
acetone $O$-methyl oxime & -2.33 & $d$ \\
acetaldehyde $N$-methyl nitrone & -1.78 & -1.41 \\
acetone $N$-methyl nitrone & -1.87 & -1.04 \\
methyl acrylate & $-0.83^{e},-0.72^{f}$ & $-0.38^{e},-039^{f}$ \\
acrylonitrile & -0.64 & -0.38
\end{tabular}

${ }^{a}$ VEA values correspond to the energy difference between the optimized neutral molecule and the radical-anion at the geometry of the optimized neutral molecule. ${ }^{b}$ AEA values correspond to the energy difference between the neutral molecule and the radical-anion at their optimized geometries. ${ }^{c}$ Reference $8 .{ }^{d}$ The radical-anion is unstable at the UB3LYP/6-311G(d,p) level of theory in gas phase and dissociates through homolytic cleavage of the $\mathrm{N}-\mathrm{O}$ bond. ${ }^{e}$ Value calculated for the s-trans isomer. ${ }^{f}$ Value calculated for the s-cis isomer.

calculated values, in parallel with the experimental redox potentials available, ${ }^{15}$ show that $N$-methylphthalimide is inherently a much better single electron transfer acceptor than any of the other model compounds examined (including acetone $^{8}$ ), which supports our initial hypothesis that these reactions are probably initiated by the chemoselective single electron transfer reduction of the phthalimido group by $\mathrm{SmI}_{2}$ to give a ketyl radical anion intermediate. ${ }^{24}$ The high yielding cyclization of $\mathbf{1}$ is a direct evidence of the facile generation

(17) Yamamoto, Y.; Maekawa, H.; Goda, S.; Nishiguchi, I. Org. Lett. 2003, 5, 2755-2758.

(18) Parrish, J. D.; Little, R. D. Org. Lett. 2002, 4, 1439-1442.

(19) Celik, H.; Ludvik, J.; Zuman, P. Electrochim. Acta 2006, 51, 58455852 .

(20) Zuman, P.; Exner, O. Collect. Czech. Chem. Commun. 1965, 30, $1832-1852$

(21) Shono, T.; Kise, N.; Fujimoto, T.; Yamanami, A.; Nomura, R. $J$. Org. Chem. 1994, 59, 1730-1740.

(22) We employed the strategy of using a relatively large basis set but without diffuse functions, which confines the excess electron to the molecular framework allowing relative estimates for molecules with negative valence electron affinities using the DFT method: (a) Li, Y.; Cai, Z.; Sevilla, M. D. J. Phys. Chem. A 2002, 106, 1596-1603. (b) Li, P.; Bu, Y.; Ai, H. J. Phys. Chem. A 2004, 108, 1200-1207).

(23) By convention, a positive EA indicates that the binding reaction of a neutral molecule with an electron is an exoergic process. For a recent review on electron affinity covering theoretical computations, see: RienstraKiracofe, J.; Tschumper, G. S.; Schaefer, H. F., III. Chem. Rev. 2002, 102, $231-282$. of this ketyl radical anion under the very mild reaction conditions used.

In conclusion, both experimental and theoretical evidence show that phthalimides are exceptionally efficient single electron transfer acceptors in reactions promoted by samarium diiodide affording ketyl radical anion intermediates, which participate in high yielding inter- and intramolecular reductive coupling processes with different radicophiles including imides, oxime ethers, nitrones, and Michael acceptors. The resultant $\alpha$-hydroxylactams are interesting advanced intermediates for the synthesis of isoindoline alkaloids and are also potential precursors of $\mathrm{N}$-acyliminium ions, ${ }^{26}$ which can further expand the synthetic value of this approach.

Acknowledgment. We thank MEC for financial support (projects BQU2003-03550-C03-02 and CTQ2006-15515C02-02/BQU) and for a predoctoral fellowship to T.V.

Supporting Information Available: Experimental procedures, spectroscopic data for the coupling products, crystallographic data of $\mathbf{2}, \mathbf{4 c}$, and $\mathbf{8}$ (minor diastereoisomer), and energies and Cartesian coordinates for new compounds in Table 1. This material is available free of charge via the Internet at http://pubs.acs.org.

\section{OL7023357}

(24) However, a note of caution on the interpretation of the quantum mechanical calculations should be added. As we stated previously, ${ }^{8}$ these theoretical results are only strictly applicable if the electron transfer is outersphere. Yet, recent studies ${ }^{25}$ led to the conclusion that the electron transfer from $\mathrm{SmI}_{2}$ in THF to a ketone carbonyl is an inner-sphere process and the same almost certainly applies to an imide carbonyl. In such a case, the electron transfer process should be influenced by the nature of the metaloxygen bond that is being formed during the reaction as well as the energy required for reorganization of the ligands around the metal center on going from oxidation state $2+$ to $3+$. In addition, as pointed out by a referee, we have to be careful when using thermodynamic arguments to support a mechanism, which requires careful kinetics studies. In the absence of these studies, we can only speculate. Since $N$-methylphthalimide is our only model substrate theoretically predicted to suffer an exothermic single electron transfer reduction $\left(E_{\mathrm{A}}>0\right),{ }^{23}$ it is expected on the basis of the Hammond postulate to have the smaller activation energy and therefore a higher rate. In agreement with this argument is the calculated planar geometry of the phthalimido ketyl radical anion, as a consequence of its delocalization in the aromatic ring, indicating that relatively little change of geometry is required to reach the transition state of the single electron transfer reaction.

(25) (a) Miller, R. S.; Sealy, J. M.; Shabangi, M.; Kuhlman, M. L.; Fuchs, J. R.; Flowers, R. A., II. J. Am. Chem. Soc. 2000, 122, 7718-7722. (b) Enemaerke, R. J.; Daasbjerg, K.; Skrydstrup, T. Chem. Commun. 1999, $343-344$.

(26) For a recent review, see: Maryanoff, B. E.; Zhang, H.-C.; Cohen, J. H.; Turchi, I. J.; Maryanoff, C. A. Chem. Rev. 2004, 104, 1431-1628. 